Preliminary. Incomplete. Do not Cite. Comments welcome.

\title{
Foreign versus Domestic Outsourcing: Firm-level Evidence on the Role of Technology
}

\author{
Eiichi Tomiura* $^{*}$ \\ Department of Economics, Yokohama National University
}

November 15, 2006

\begin{abstract}
The decision about where to outsource varies across firms and industries. General machinery heavily depends on domestic subcontractors, while outsourcing overseas is prevalent in apparel. Based on firm-level data explicitly distinguishing foreign outsourcing from domestic outsourcing in all manufacturing industries, this paper finds that firms tend to prefer domestic outsourcing to foreign outsourcing when they are R\&D-intensive. This finding is consistent with incomplete contracting models, since technologically complex products are likely to require the high quality of contracting environment and the assembler-supplier proximity for customization. This paper also finds that firms connected with computer networks are actively outsourcing.
\end{abstract}

JEL Classifications: F12; F23; D20; F14.

Keywords: foreign outsourcing; heterogeneity; firm-level data; R\&D intensity; network

\footnotetext{
* Eiichi Tomiura, Department of Economics, Yokohama National University, 79-4 Tokiwa-dai, Hodogaya-ku, Yokohama City, 240-8501, Japan. Phone: +81-(0)45-339-3563. Fax: +81-(0)45-339-3574, E-mail: tomiura@ynu.ac.jp.
} 


\section{Introduction}

Outsourcing is increasing its importance in a wide range of firms and industries. While many assemblers have long been outsourcing to subcontractors in proximate locations, outsourcing across borders has been facilitated by information technology development and trade liberalization in recent years. Outsourcing to low-wage countries appears particularly prevalent in firms producing apparel and other labor-intensive goods, as in Nike, the company outsourcing most of its manufacturing tasks across borders. On the other hand, assemblers of technologically complex products tend to depend heavily on domestic suppliers. For example, Toyota employs the just-in-time procurement of customized auto parts from nearby suppliers. The relationship between technology and foreign outsourcing is worth investigating.

The firm's decision about where to outsource has recently been formalized by the incomplete contract theory. For example, in the model by Grossman and Helpman (2005), the production is supposed to require a customized input manufactured by an independent supplier with a relation-specific investment, governed by an incomplete contract. A final assembler searches for a partner supplier whose expertise is close to its input requirement, either in the technologically and legally advanced home country North or in the low-wage foreign country South.

Their model predicts that a firm tends to choose domestic outsourcing rather than foreign outsourcing when the firm's product is more technologically complex. The factors behind this choice can be listed as follows. First, the cost of customizing inputs is likely to be especially high among Southern suppliers, many of whom are not equipped with computer-aided design. Second, these complex products tend to require the high-quality legal system for verification/contracting. Third, the assembler-supplier proximity is often critical in customizing complex products. Finally, the input market for these technologically advanced 
products tends to be thicker in North. Many other recent theoretical models of incomplete contracting are also in line with this prediction (e.g. Antràs, 2005; Acemoglu et al., 2006; Feenstra and Spencer, 2005).

By using firm-level data, this paper empirically examines how the technology is related with the firm's choice between foreign outsourcing versus domestic outsourcing. This paper uses unique and direct data on outsourcing, where contracts with foreign suppliers are explicitly distinguished from those with domestic suppliers. The data set covers 118,300 firms in all manufacturing industries in Japan without any firm-size threshold. A wide range of corporate variables are also included, such as sales, employment, capital, R\&D expenditure, foreign affiliates, and computer network connection.

To preview the principal results, firms tend to outsource within the home country rather than across borders when they are R\&D-intensive. This paper first uses the multinomial logit model on the firm's location choice in outsourcing, but confirms the robustness of the results by the Heckman's two-step estimation procedure with the yen value ratio of outsourced tasks. Descriptive statistics derived from firm-level data are generally consistent with the regression results, and also reveal notable inter-industry variations.

The rest of this paper is organized as follows. Section 2 briefly describes the data. Section 3 summarizes descriptive statistics. Section 4 explains empirical specifications and reports firm-level estimation results. Section 5 concludes.

\section{Data description}

All the data used for this paper are derived from The Basic Survey of Commercial and Manufacturing Structure and Activity (Sho-Kogyo Jittai Kihon Chosa in Japanese). ${ }^{1}$ The survey

\footnotetext{
1 Any researcher can access to the same original firm-level data files by obtaining individual official permission from the government in advance, though confidential micro data cannot be publicly
} 
covers 118,300 firms in all manufacturing industries without any firm-size threshold. ${ }^{2}$ Hence, we can interpret this survey as a relatively precise representation of the whole manufacturing in Japan. The survey contains a wide range of variables, such as sales, employment, capital, R\&D expenditure, the computer network connection, and foreign affiliates. This survey was conducted only once at 1998.

The limited availability of micro-data has prevented previous empirical studies from investigating the location choice in outsourcing. ${ }^{3}$ As a unique measure of foreign outsourcing, the survey collects data on the yen values of manufacturing or processing tasks contracted out (gaichu in Japanese) to suppliers located in foreign countries, explicitly distinguished from those contracted out to firms located in Japan. ${ }^{4}$ This definition successfully excludes intermediates purchased at the marketplace, which inevitably contaminate foreign outsourcing measures dependent on intermediate import data. Though the survey does not contain any data on the supplier's characteristics other than this foreign-domestic distinction, this measure is relatively direct and appropriate for our analysis of the firm's choice between foreign vs. domestic outsourcing.

\section{Descriptive statistics}

This section summarizes descriptive statistics derived from the firm-level data. Firms are grouped by their involvement in outsourcing or by industries.

\subsection{Comparison of averages}

Table 1 disaggregates all the surveyed 118,300 firms into the following four disjoint groups: (1)

\footnotetext{
disclosed.

2 This paper focuses on manufacturing industries because the survey captures outsourcing of production-related tasks, as will be explained in the next paragraph.

${ }^{3}$ Few studies have distinguished outsourcing locations at the firm/plant level. As a rare example, Görg and Hanley (2003) include the ratio of imported inputs over total inputs in the productivity regression for electronics plants in Ireland, yet the choice of location is not examined.

${ }_{4}^{4}$ Tomiura (2005) explains the survey's definition of outsourcing in detail.
} 
FO \& DO (firms with foreign and domestic outsourcing both strictly positive), (2) FO only (firms with positive foreign outsourcing but no domestic outsourcing), (3) DO only (firms with positive domestic outsourcing but no foreign outsourcing), and (4) No Out (firms outsourcing no production at all).

Several contrasts in Table 1 are noteworthy. As shown in the row (1), only around 3\% of the surveyed firms are outsourcing across borders, while nearly half of them are outsourcing within the home country. On the other hand, around half of the firms are sourcing exclusively in-house or depend totally on intermediates available at marketplace. While the outsourcing in this survey does not cover non-production services, this extremely low share of foreign outsourcers should be noted. ${ }^{5}$ The firms outsourcing to foreign suppliers are normally outsourcing also to domestic suppliers, reflecting varying difficulties in matching. As a result, the firms involved only in foreign outsourcing are extremely rare $(0.2 \%)$.

As the row (2) confirms, foreign outsourcers are on average substantially larger in size than domestic outsourcers. In our sample, domestic outsourcers tend to be larger than the firms without any outsourcing. These imply that large-sized firms tend to have advantages in outsourcing, especially foreign outsourcing, possibly due to their strong bargaining position or established reputation in the markets. Or alternatively, only large-sized firms may overcome high fixed entry costs for foreign outsourcing possibly because contracting with firms in different legal systems requires rich headquarter functions within a firms (e.g. Antràs and Helpman, 2004; Grossman et al., 2005). The survey, however, contains no data related with management or human skills.

The row (3) shows that the frequency of firms with positive R\&D spending among FO

\footnotetext{
5 Since all the firms with no less than 50 employees (those more likely to be FO firms) are surveyed with certainty but those with less than 50 are sampled with probability of less than one, the share of foreign outsourcers must be even lower in the entire population. The sampling frequency for each cell is not disclosed, and thus cannot be adjusted.
} 
\& DO firms is higher than that in FO only or DO only firms, which is in turn higher than that in No Out firms. However, this observed gap in R\&D frequency must be at least partially due to the gap in firm size, since the R\&D frequency ordering in the row (3) is the same as the firm size ordering in the row (2). Moreover, small-sized firms tend to record no official R\&D expenditures, even when they are actively improving production processes. On the other hand, when we compare $R \& D$-sales ratio among R\&D-active firms in the row (4), No Out firms, which include totally integrated firms, tend to have relatively high R\&D intensity. No noticeable differences are observed across other three groups.

On the factor intensity, the row (5) reveals that foreign outsourcers are on average more capital intensive than domestic outsourcers or No Out firms. The capital-labor ratios (tangible fixed assets divided by the number of regular employees) in the table appear consistent with the fact that Japan is more capital-abundant than neighbouring Asian low-wage countries. However, the observed gap is slim. Furthermore, we cannot estimate the factor content of outsourced activities from our data. Another scenario consistent with this result may be that only capital-intensive firms can engage in foreign outsourcing due to high fixed entry costs.

The row (6) demonstrates that outsourcers (foreign or domestic), especially $F O \& D O$ firms, tend to be actively connected with computer networks. ${ }^{6}$ The firms without any outsourcing contracts are the least active in this regard. These indicate that the use of computer networks is critical for finding potential partners and coordinating tasks with contracted suppliers.

As shown in the row (7), foreign outsourcers are on average far more often operate affiliates overseas compared with domestic outsourcers or No Out firms. ${ }^{7}$ This suggests that the

6 “Computer networks" include inter-firm, open, and local area networks (LAN).

7 Affiliates overseas in the survey are majority-owned subsidiaries, minority-owned affiliates, and branch offices/plants (jigyousho in Japanese). The survey contains no quantitative data on foreign affiliates, such as local procurement or offshore employment. 
operation of foreign affiliates may facilitate matching with foreign suppliers, ${ }^{8}$ though this difference must be again partly attributable to the gap in firm size.

Although these figures sound consistent with our priors, we need to control for these factors simultaneously in regression formats in Section 4.

\subsection{Comparison of industries}

As industry-specific factors inevitably affect the firm's outsourcing decision, Table 2 compares 22 two-digit industries. The following three shares are displayed: (A) general outsourcers (foreign and domestic combined) in all firms, (B) foreign outsourcers in general outsourcers, and (C) tasks outsourced to foreign suppliers in total outsourced tasks. The first two shares are on the number of firms, while the last is on the value in yen. ${ }^{9}$

Cross-industry variations are remarkable in Table 2. First, column (A) confirms substantial differences in the extent of outsourcing. The industry with the highest percentage of outsourcers is general machinery (73\%), followed by printing, transport equipment, electric machinery, and precision instruments. On the other hand, merely around $13-15 \%$ of the firms are outsourcing production in food and beverage industries.

Second, as reported in column (B), however, many industries are arrayed differently when we look at the extent of foreign outsourcing compared with general outsourcing. Among the industries most actively outsourcing, general machinery and transport equipment industries are ranked nearly in the middle in the ordering in foreign outsourcing. Furthermore, the printing industry, which is with the second highest share of outsourcers, is one of the industries with

\footnotetext{
8 The outsourcing in the survey is defined by contracting out to "other firms," which can include foreign affiliates when they are independent legal entities. This issue will be again discussed in the regression section.

9 The share of outsourced tasks relative to costs is not calculated because the survey contains no economic cost data. As an alternative, Tomiura (2005) reports the share of FO value relative to sales.
} 
lowest share of FO in general outsourcers. On the other hand, apparel, leather, and rubber are ranked relatively high in FO, while electric machinery and precision instruments occupy similarly high ranks in both columns (A) and (B).

Finally, as shown in column (C), inter-industry contrasts are clear also in terms of the value of outsourced tasks. Among the industries actively involved in general outsourcing, electric machinery and precision instruments are outsourcing high share of tasks across borders, while most of the outsourced tasks in the printing industry are accomplished within the home country.

These figures in the three columns indicate that industries can be classified into the following four groups: (a) industries actively outsourcing both within and across borders (e.g. electric machinery, precision instruments), (b) industries actively outsourcing but mostly within the home country (e.g. printing, general machinery, transport equipment), (c) industries active in foreign outsourcing compared with general outsourcing (e.g. apparel, leather, rubber), and (d) industries inactive in outsourcing (e.g. food, beverage). These cross-industry contrasts are consistent with our daily observations. For example, manufacturing processes in electronics industries tend to be relatively standardized, and easily fragmented around the globe, and components are tradable across borders. ${ }^{10}$ Printing tasks outsourced from Japanese firms almost inevitably require extensive knowledge of Japanese language. Outsourcing of production often requires proximate supplier-assembler contacts in technologically complex and highly differentiated industries, such as general machinery and transport equipment. Labor-intensive industries tend to actively seek low-wage subcontractors for their technologically simple products.

10 Grossman et al. (2005) show that "in an industry with a larger fraction of firms engage in outsourcing, a larger fraction of firms source their intermediate inputs in the South" when "the economies of scope in management exceed the managerial overload of integration" (p.22). They do not discuss which industry satisfies this condition, however. 
Although substantial differences are observed across industries, the next section reports firm-level regressions to investigate intra-industry variations.

\section{Firm-level regressions}

While the descriptive statistics reported in the previous section are rather self-explanatory, this section controls for various factors in regression formats as follows.

\subsection{Empirical specifications}

This paper uses the following reduced-form:

$$
\text { Out }=\alpha+\beta_{1} \ln \left(\frac{R \& D}{Q}\right)+\beta_{2} \ln Q+\beta_{3} \ln \frac{K}{L}+\beta_{4} N e t+\beta_{5} F D I+\gamma N D+u .
$$

The dependent variable Out is the firm's choice of outsourcing. Although Grossman and Helpman (2005) concentrate on the binary choice of FO vs. DO, some multiple-task firms in the real world are simultaneously engage in both foreign and domestic outsourcing, as reported in Table 1. Hence, this paper considers the following mutually-exclusive four categories: (a) FO \& DO, (b) FO only, (c) DO only, and (d) No Out in the multinomial logit model. Since the data set is in a cross-section format, one should not interpret the above regression as showing the direction of causality.

The explanatory variables are (a) $R \& D$ intensity (percentage $R \& D$-sales ratio ${ }^{11}$ ) $R \& D / Q$, (b) firm size $Q$ (sales), (c) capital-labor ratio $K / L$, (d) the dummy indicating the firm's connection with computer networks Net, (e) the dummy for the firm's operation of affiliates overseas FDI, and (f) 2-digit industry dummy variables IND. The error term is denoted by $u$. All variables, other than dummies, are in logarithms.

To investigate the prediction by Grossman and Helpman (2005), this paper chooses R\&D intensity as a proxy for the technological complexity. This proxy has already been used for

11 To include firms without official R\&D, this paper adds negligible $10^{-8}$ before taking logarithm. 
similar purposes (e.g. Acemoglu et al., 2005). Compared with matured standardized commodities, R\&D-intensive products are likely to require many differentiated inputs satisfying high and unique requirements, even in some cases protected by patents. R\&D expenditures internal to each firm are often made for technologies specific to the firm's mix of products. Market imperfections associated with technology are likely to turn $R \& D$ investment into relation-specific investment. Outsourcing contracts tend inevitably to be more incomplete for such products, as the performance of suppliers should be less predictable and/or less verifiable. These factors, typically examined in incomplete contract models, suggest that the coefficient on R\&D intensity $\beta_{1}$ is positive for the choice of domestic outsourcing and negative for FO. The empirical investigation of this hypothesis is the main target of this paper.

This prediction is also consistent with a wide variety of other recent models of incomplete contracting. For example, Feenstra and Spencer (2005) predict that relation-specific investment, which is likely to result in product customization, makes firms prefer DO to FO, though DO data are not available in their dataset on Chinese processing trade. In their analysis of pairs of supplying-producing industries, Acemoglu et al. (2005) predict outsourcing more likely when the producing industry is less technology intensive, with supportive evidence from U.K. industry data. Acemoglu et al. (2006) prove that greater contractual incompleteness reduces supplier investments and leads to the adoption of less advanced technology. Neither of these two papers, however, discusses the foreign vs. domestic decision in outsourcing. Antràs (2005) constructs a model showing that firms outsource overseas in the last stage along the Vernon-type product cycle. While they focus on different aspects, all these studies are basically in line with the negative relation between foreign outsourcing and technological complexity. ${ }^{12}$

12 Glass and Saggi (2001) argue that increased profit by FO creates greater incentives for innovation, but do not consider DO or incomplete contracts. R\&D or technology choice is not examined in the models on the four-way choice (integration vs. outsourcing as well as foreign vs. domestic) by Antràs and Helpman (2004) or Grossman et al. (2005). 
Other right-hand side variables in (1) are expected to have the signs as follows. First, large-sized firms should be active in outsourcing not only within the home country but also across borders because they generally have strong bargaining position and/or rich management skills necessary for contracting, especially for international contracting. Second, capital-intensive firms find profitable to outsource abroad. As the thick market effect in Grossman and Helpman (2005) suggests, capital-intensive Japanese final assemblers are more likely to turn up a partner supplier for outsourcing labor-intensive tasks in neighbouring low-wage Asian countries where more input suppliers are active in these tasks, compared with labor-scarce Japan. An alternative scenario that only capital-intensive firms can overcome entry costs for foreign outsourcing is observationally equivalent in the reduced-form (1). Third, the computer network connection should be positively related with outsourcing, since it reduces search costs and facilitates business-to-business matching, and since contracting tends to be relatively easy on information-based transparent tasks. Finally, the operation of foreign affiliates should facilitate contacts with potential foreign subcontractors and thus enhance foreign outsourcing.

The control of industry-specific factors is also important to discuss the technological complexity of products. For example, the chemical products are normally characterized by their high R\&D-sales ratios, but tend to depend on few customized parts and components.

While the equation (1) concentrates on the discrete choice between foreign vs. domestic outsourcing, the survey contains the data on how much the firm is outsourcing within and across borders, respectively. To exploit this important information, this paper estimates the following alternative specification:

$$
\frac{D O V}{F O V+1}=\mu+\delta_{1} \ln \left(\frac{R \& D}{Q}\right)+\delta_{2} \ln Q+\delta_{3} \ln \frac{K}{L}+\delta_{4} N e t+\delta_{5} F D I+\eta I N D+v .
$$

The dependent variable is now replaced by the ratio of tasks outsourced to domestic suppliers 
$D O V$ over those to foreign suppliers FOV, both of which are measured in terms of yen value. To include many firms without foreign outsourcing into the regression, this paper adds the value of one to the denominator. This continuous ratio is another appropriate measure because firms in the real world normally perform many tasks or production processes, each of which can be formalized by the binary foreign-vs.-domestic decision of a one-task firm (assembler) considered in Grossman and Helpman (2005). ${ }^{13}$ The theory predicts that the coefficient on R\&D intensity in (2) should be positive. The error term is expressed by $v$.

This paper estimates the equation (2) by the Heckman's two-step procedure. In the first-stage, the selection equation (outsourcing or not) is estimated by probit. ${ }^{14}$ The variables on the right-hand side are kept the same to facilitate comparisons with (1). In the second-stage, the equation (2) for the DO-FO ratio is estimated with the selectivity correction. The same explanatory variables are used both in the first- and second-stage equations, as no theoretical priors are imposed.

\subsection{Estimation results}

Table 3 reports the estimation results from the multinomial logit model. ${ }^{15}$ Industry-specific factors are controlled by the dummy variables. Heteroskedasticity-robust standard errors are in parentheses. The base category is the choice of domestic outsourcing only.

As the most notable finding, low R\&D intensity is significantly related with the choice of foreign outsourcing relative to domestic outsourcing. This finding suggests that foreign outsourcing is more likely to be prevalent in technologically simpler, more standardized, or less

\footnotetext{
13 Shy and Stenbacka (2005) consider multiple inputs for a manufacturer and derive the equilibrium fraction of outsourced inputs, though they do not distinguish FO in outsourcing. 14 Since $F O$ only firms are exceptional, this paper focuses on the choice of $D O$ or not in the first-stage selection equation.

15 The firms without $K$ data are excluded from regressions.
} 
customized products, as consistent with the theoretical prediction by Grossman and Helpman (2005). ${ }^{16}$

Other results are also noteworthy. Large-sized firms tend to choose foreign outsourcing, corroborating the descriptive statistics in Table 1. Foreign outsourcing is preferred when the firms are capital-intensive or connected with computer networks. The operation of affiliates overseas appears positively related with foreign outsourcing, though the relation is insignificant for the exceptional category FO only. On the other hand, the firms inactive in outsourcing tend to be not R\&D-intensive compared with domestic outsourcers, small in size, labor-intensive, not connected with computer networks, or source overseas in-house from FDI-integrated subsidiaries. These findings are generally consistent with our expectations.

Next, Table 4 reports the estimation result from the Heckman's two-step procedure. ${ }^{17}$ The signs of all coefficients estimated by the first-stage probit equation ( $D O$ or not) are confirmed consistent with the logit estimates on the choice of No Out against $D O$ in Table 3.

As the most notable finding from the second-stage regression, higher R\&D intensity is related with significantly more tasks outsourced to domestic suppliers relative to foreign suppliers in the yen value. ${ }^{18}$ Thus, our previous result from the multinomial choice model is confirmed robust even with this continuous ratio.

The Heckit estimates reveal other interesting results as well. First, fixed entry costs for outsourcing appear non-negligible, as implied by the significant inverse Mill’s ratio. Moreover, larger-sized firms tend to significantly more often start outsourcing, but the dependence on foreign outsourcing does not rise proportionally with the firm size. The firm size here may work

16 Some firms may manufacture multiple products with varying R\&D intensities, but product-specific $R \& D$ data within a firm are not available.

17 Robust standard errors for Heckit are estimated by bootstrap with 200 iterations. The heteroskedasticity-consistent maximum-likelihood estimation did not converge within a reasonable number of iterations.

18 This finding on the continuous share is consistent with Shy and Stenbacka (2005), as they predict that the fraction of outsourced inputs decreases with the technological complexity. 
as a proxy for headquarter functions, which are required upon entry into outsourcing contracts. The significantly positive coefficients on R\&D intensity and on capital intensity are also in line with this interpretation. R\&D-active or capital-intensive firms tend to relatively easily start outsourcing possibly because they are likely to have employees handling complex legal and coordination work or due to economies of scale, but they tend to have fewer manufacturing tasks technologically simple enough to be outsourced to foreign suppliers.

Second, firms tend to outsource significantly more of their tasks within the home country when they are more capital-intensive. Labor-intensive tasks are relatively easy to be outsourced overseas, typically to low-wage countries. ${ }^{19}$ This finding confirms the previous report in Tomiura (2005), and is consistent with the theoretical prediction by Antràs (2003). ${ }^{20}$

Third, the connection with computer networks is significantly related with outsourcing in general, not particularly with foreign outsourcing. This implies that information technology development facilitates business matching in any location.

Finally, the firms operating foreign affiliates are not actively start outsourcing, but tend to outsource more to foreign suppliers once they engage in outsourcing. Foreign affiliates are likely to work as an important facilitating channel for matching with foreign suppliers, not with domestic suppliers, while intra-firm sourcing from these FDI-integrated foreign affiliates at least partly substitutes arm's-length outsourcing procurement. ${ }^{21}$

\section{Concluding remarks}

This paper has investigated the firm's choice between foreign and domestic outsourcing, based

19 The rise of $K / L$ as a result of active $F O$ of labor-intensive tasks in the past is not detected in our cross-section data.

20 Antràs (2003) predicts active FO in labor-intensive sectors, though he compares FO with intra-firm sourcing from FDI affiliates, not with DO.

21 Though FO in the survey can include procurements from FDI affiliates, this regression result confirms that the statistical contamination due to this inclusion appears minor. 
on a firm-level data set covering 118,300 firms in all manufacturing industries without any firm-size threshold. The empirical findings are consistent with the theoretical prediction. R\&D intensity is found negatively related with the extent of foreign outsourcing relative to domestic outsourcing. This result is one of the earliest direct evidence on the relationship between technological complexity and the choice of outsourcing location at the firm level.

To cement the generality of this finding, however, several attempts will be desirable in future independent studies. At the aggregate sector level, intermediate import data derived from input-output tables can be combined with $R \& D$ data. One will also find it interesting to seek micro data on foreign outsourcing of non-production services, linked with data on human skills at the firm level, preferably in a longitudinal format.

\section{Acknowledgement}

The Ministry of Internal Affairs allowed the author to access the government micro-data files by issuing official approvals. Kei Nara and Mutsuharu Takahashi were helpful for the data access. The author acknowledges valuable comments from participants at Asia Pacific Trade Seminar and European Trade Study Group. This research was partly financed by Grant-in-Aid for Scientific Research. Remaining errors are mine.

\section{References}

Acemoglu, D., Aghion, P., Griffith, R., and Zilibotti, F. (2005) "Vertical integration and technology: theory and evidence,” http://econ-www.mit.edu/faculty/download_pdf.ph p?id=1041.

Acemoglu, D., Antràs, P., and Helpman, E. (2006) "Contracts and technology adoption," http://post.economics.harvard.edu/faculty/helpman/papers/ContractsAndTechnology.pdf.

Antràs, P. (2003) “Firms, contracts, and trade structure,” Quarterly Journal of Economics 118, 1375-1418.

Antràs, P. (2005) “Incomplete contracts and the product cycle,” American Economic Review 95, 1054-1073.

Antràs, P., and Helpman, E. (2004) “Global sourcing,” Journal of Political Economy 112, 552-580.

Feenstra, R., and Spencer, B. (2005) "Contractual versus generic outsourcing: the role of 
proximity,” NBER Working Paper No. 11885.

Görg, H., and Hanley, A. (2003) "International outsourcing and productivity: evidence from plant level data,” GEP Research Paper 2003/20, University of Nottingham.

Glass, A., and Saggi, K. (2001) "Innovation and wage effects of international outsourcing," European Economic Review 45, 67-86.

Grossman, G., Helpmam, E., and Szeidl, A. (2005) "Complementarities between outsourcing and foreign sourcing,” American Economic Review 95 Papers and Proceedings, 19-24.

Grossman, G., and Helpman, E. (2005) “Outsourcing in a global economy,” Review of Economic Studies 72, 135-159.

Shy, O., and Stenbacka, R. (2005) "Partial outsourcing, monitoring cost, and market structure," Canadian Journal of Economics 38, 1173-1190.

Tomiura, E. (2005) "Foreign outsourcing and firm-level characteristics: evidence from Japanese manufacturers,” Journal of the Japanese and International Economies 19, 255-271. 
Table 1 Comparison of averages and shares

\begin{tabular}{|c|c|c|c|c|}
\hline & FO \& DO & FO only & DO only & No Out \\
\hline $\begin{array}{c}\text { (1) Share } \\
\text { (\% in total number of firms) }\end{array}$ & 2.48 & 0.20 & 46.52 & 50.81 \\
\hline $\begin{array}{c}\text { (2) Average Firm Size (in sales) } \\
\text { (relative to No Out) }\end{array}$ & 20.99 & 6.93 & 2.57 & 1 \\
\hline $\begin{array}{c}\text { (3) Firms active in R\&D } \\
\text { (\% within each group) }\end{array}$ & 46.16 & 28.21 & 22.22 & 9.97 \\
\hline $\begin{array}{c}\text { (4) Average R\&D-Sales Ratio } \\
\text { (\%) }\end{array}$ & 2.49 & 2.59 & 2.37 & 3.48 \\
\hline $\begin{array}{c}\text { (5) Average Capital-Labor Ratio } \\
\text { (relative to No Out) }\end{array}$ & 1.15 & 1.15 & 0.98 & 1 \\
\hline $\begin{array}{c}\text { (6) Firms connected with } \\
\text { computer networks (\%) }\end{array}$ & 52.13 & 33.76 & 31.33 & 13.61 \\
\hline $\begin{array}{c}\text { (7) Firms operating } \\
\text { affiliates overseas (\%) }\end{array}$ & 26.22 & 27.35 & 3.99 & 1.26 \\
\hline
\end{tabular}

Notes: All 118,300 firms are included. The rows (3), (6), and (7) display the percentage within each group. 
Table 2 Comparison across industries

\begin{tabular}{|c|c|c|c|}
\hline INDUSTRY & $\begin{array}{c}\text { (A) } \\
\frac{\text { Outsourcers }}{\text { All firms }}\end{array}$ & $\begin{array}{c}\text { (B) } \\
\text { FO firms } \\
\text { Outsoucers }\end{array}$ & $\begin{array}{c}\text { (C) } \\
\frac{\text { FO value }}{\text { Out value }}\end{array}$ \\
\hline 12. Food manufacturing & 14.60 & 3.66 & 3.17 \\
\hline 13. Beverage, Tobacco \& Feed & 12.55 & 4.05 & 0.47 \\
\hline 14. Textile & 48.68 & 3.49 & 0.62 \\
\hline 15. Apparel \& Textile products & 51.28 & 6.43 & 5.56 \\
\hline 16. Timber \& Wooden products & 28.43 & 4.36 & 5.90 \\
\hline 17. Furniture \& fixture & 52.10 & 3.76 & 2.41 \\
\hline 18. Pulp \& Paper products & 45.69 & 4.53 & 3.71 \\
\hline 19. Printing \& Publishing & 68.81 & 3.76 & 0.20 \\
\hline 20. Chemical products & 31.72 & 5.92 & 1.95 \\
\hline 21. Petroleum \& Coal products & 23.20 & 5.95 & 0.04 \\
\hline 22. Plastic products & 53.01 & 4.03 & 5.13 \\
\hline 23. Rubber products & 39.49 & 8.36 & 9.30 \\
\hline 24. Leather \& Fur products & 41.63 & 9.07 & 9.89 \\
\hline 25. Ceramic, Stone \& Clay products & 31.34 & 3.74 & 4.75 \\
\hline 26. Iron \& Steel & 52.13 & 4.88 & 0.64 \\
\hline 27. Nonferrous Metals & 51.25 & 4.68 & 1.70 \\
\hline 28. Metal products & 60.57 & 3.77 & 0.66 \\
\hline 29. General Machinery & 73.73 & 5.88 & 3.88 \\
\hline 30. Electric Machinery & 61.84 & 7.42 & 14.29 \\
\hline 31. Transportation Equipment & 64.72 & 5.51 & 2.78 \\
\hline 32. Precision Instruments & 60.71 & 6.82 & 17.04 \\
\hline 34. Miscellaneous manufacturing & 53.39 & 8.82 & 8.06 \\
\hline All manufacturing combined & 49.19 & 5.44 & 6.35 \\
\hline
\end{tabular}

Notes: All shares are in percentage based on the number of firms. All 118,300 firms are covered. The ordnance industry (33) is merged into the general machinery (29). 
Table 3 Multinomial logit estimation

\begin{tabular}{|c|cc|cc|cc|}
\hline & \multicolumn{2}{|c|}{$F O \&$ DO } & \multicolumn{2}{c|}{ FO only } & \multicolumn{2}{c|}{ No Out } \\
\hline R\&D/Sales & -0.0101 & $(0.0019)$ & -0.1704 & $(0.0097)$ & -0.0226 & $(0.0011)$ \\
\hline Size & 0.1220 & $(0.0129)$ & 0.2540 & $(0.0266)$ & -0.3647 & $(0.0059)$ \\
\hline K/L & 0.0598 & $(0.0128)$ & 0.0916 & $(0.0198)$ & -0.0405 & $(0.0058)$ \\
\hline Net & 0.8350 & $(0.0379)$ & 1.2599 & $(0.0658)$ & -0.1846 & $(0.0196)$ \\
\hline FDI & 1.2909 & $(0.0682)$ & -0.5391 & $(0.3568)$ & 0.7287 & $(0.0639)$ \\
\hline \multicolumn{4}{|c|}{ Log pseudo-likelihood $=-71742.843$, Pseudo $\mathrm{R}^{2}=0.2279$} \\
\hline
\end{tabular}

Notes: 110,987 firms are covered. The base category is $D O$ only. Industry dummies are included. Robust standard errors are in parentheses. Explanatory variables, except dummies, are in logarithm.

Table 4 Heckman's two-step estimation

\begin{tabular}{|c|c|c|}
\hline & $\begin{array}{c}\text { DOV/(FOV+1) } \\
\text { (value ratio) }\end{array}$ & $\begin{array}{c}\text { DO or Not } \\
\left(1^{\text {st }} \text {-stage Selection) }\right.\end{array}$ \\
\hline$R \& D /$ Sales & $407.6(134.9)$ & $0.0140(0.0005)$ \\
\hline Size & $5094.2(1617.6)$ & $0.1485(0.0032)$ \\
\hline$K / L$ & $938.7(328.7)$ & $0.0301(0.0030)$ \\
\hline Net & $7253.9(2358.0)$ & $0.2527(0.0098)$ \\
\hline FDI & $-7858.3(2887.0)$ & $-0.2766(0.0276)$ \\
\hline Inverse Mill's ratio & $60094.0(19646.3)$ & $\left(\right.$ Wald $\left.\chi^{2}=77.70\right)$ \\
\hline
\end{tabular}

Notes: Among 110,987 firms used for estimation, 39,476 are censored. Industry dummies are included in the second-stage regression. Robust standard errors are in parentheses. Explanatory variables, except dummies, are in logarithm. 